\title{
Resistencia química del hormigón XXII. Influencia de la adición de escoria a un cemento portland de alta resistencia inicial. Estudio de la concentración iónica del sistema: cemento 1 /escoria-agua de mar artificial
}

DEMETRIO GASPAR-TEBAR y JOSE LUIS SAGRERA-MORENO

Drs. en Ciencias Químicas

ITECC/CSIC

\begin{abstract}
$R E S U M E N$
En el presente trabajo, continuación de otros, se estudia la variación del $\mathrm{pH}$, asi como de la concentración de los iones Ca (II), $\mathrm{Mg}$ (II), $\mathrm{SO}_{4}(\mathrm{II})$ y $\mathrm{Cl}$ (I) del agua de mar artificial (ASTM D 1141-75) en donde han estado sumergidas las series de probetas de mortero $(1: 3)$ hechas con un cemento portland industrial de alta resistencia inicial (cemento $1<>P-550-A R I$ ) y con las mezclas cemento $1 /$ escoria $=85 / 15-65 / 35-40 / 60$ y 30/70, en peso, durante $56-90-180$ y 360 días (periodos de conservación-ataque), en esta etapa, después del periodo de curado (1 día en cámara húmeda y 21 días bajo agua potable filtrada). Así mismo, se estudia el contenido de los iones $\mathrm{Ca}$ (II), $\mathrm{Mg}$ (II) y $\mathrm{SO}_{4}$ (II) de las nuevas fases sólidas formadas en dichos medios de conservación-ataque. La composición estructural de dichas fases sólidas y de la fracción enriquecida de las mencionadas probetas de mortero se determinó por DRX, de ello se dió cuenta en (3).

En los casos estudiados se ha puesto de manifiesto que se produce un incremento de Ca (II) en la disolución y en las nuevas fases sólidas, asi como del valor del $p H$, que dependen de la mezcla utilizada para fabricar las diversas series de probetas de mortero y del tiempo de conservación-ataque. Dichas cantidades de Ca (II) experimentan, para cada edad, una fuerte disminución conforme la cantidad de cemento 1 de la mezcla es menor $y$ un incremento, para cada mezcla, conforme aumenta el tiempo de conservación-ataque; este incremento es suave para el caso de los medios en donde han estado sumergidas las probetas hechas con las mezclas que tienen los mayores contenidos de escoria (60 y $70 \%$, en peso). Si, además, se tiene en cuenta el contenido de Ca (II) en el agua de mar artificial ASTM el proceso de disolución de Ca (II) es aditivo.
\end{abstract}

El contenido de $\mathrm{Mg}$ (II) del agua de mar artificial ASTM $\left(4,43 \times 10^{-2}\right.$ moles $\left./ 800 \mathrm{ml}\right)$ experimenta en todos los casos estudiados una disminución que es función de la mezcla utilizada en la fabricación de las diversas series de probetas de mortero y del tiempo de

\begin{abstract}
$S U M M A R Y$
In this present work, a continuation of others, there is studied the variation of $\mathrm{pH}$, as likewise the concentration of the ions $\mathrm{Ca}(\mathrm{II}), \mathrm{Mg}(\mathrm{II}), \mathrm{SO}_{4}(\mathrm{II})$ and $\mathrm{Cl}(\mathrm{I})$ of artificial sea water (ASTM D 1141-75) in which there have been submerged the series of test speciments of mortar (1:3) made with an industrial Portland cement of high initial resistance (cement $1<>P-550-A R I$ ) and with the mixtures cement $1 /$ slag $=85 / 15-65 / 35-40 / 60$ and $30 / 70$, in weight, during $56-90-180$ and 360 days (periods of conservation-attack), in this stage, after the curing period (1 day in damp chamber and 21 days under filtered drinking water). There is likewise studied the content of the ions $\mathrm{Ca}$ (II), $\mathrm{Mg}$ (II) and $\mathrm{SO}_{4}$ (II) of the new solid phases formed in said means of conservation-attack. The structural composition of said solid phases and of the enriched fraction of the test speciments of mortar referred to was determined by DRX, of this an account was given in (3).
\end{abstract}

In the cases studied it was evident that there is produced an increase of $\mathrm{Ca}$ (II) in the dissolution of the new solid phases, and likewise of the value of $\mathrm{pH}$, which depend on the mixture utilized for the manufacture of the different series of test speciments of mortar and on the time of conservation-attack. Said quantities of $\mathrm{Ca}$ (II) experience, for each age, a strong decrease, if the quantity of cement 1 of the mixture is less, and an increase, for each mxture, if the time of conservation-attack is increased; this increase is mildfor the case of the means in which there have been submerged the test speciments made with the mixtures which have the greater content of slag (60 and $70 \%$ ) in weigh. If, moreover, there is borne in mind the content of Ca (II) in the artificial sea water ASTM, the process of dissolution of $\mathrm{Ca}$ (II) is additive.

The content of $M g(I I)$ of the artificial sea water $\operatorname{ASTM}\left(4.43 \times 10^{-2}\right.$ mols. $\left./ 800 \mathrm{ml}\right)$ experiences in all the cases studied a decrease which is a function of the mixture utilized in the manufacture of the different series of test speciments of mortar and of the time of conservation-attack, which have an influence in the 
conservación-ataque, que influyen en las condiciones del medio $y$, de un modo especial, en la concentración de grupos $\mathrm{OH}$ (I). El ion $\mathrm{Mg}$ (II) ha desaparecido, prácticamente, del agua de mar artificial en donde han estado sumergidas las probetas de mortero hechas con cemento 1 y con la mezcla que tiene $15 \%$ de escoria, en peso; en los restantes medios se ha detectado el ion Mg (II) en cantidades variables según la mezcla utilizada en la elaboración de las probetas. El ion Mg (II) se ha encontrado en las nuevas fases sólidas formadas en el agua de mar artificial en donde han estado sumergidas las series de probetas fabricadas con cemento 1 y con la mezcla que tiene $15 \%$ de escoria; ha precipitado como brucita.

El contenido de $\mathrm{SO}_{4}(\mathrm{II})$ del agua de mar artificial ASTM $\left(2,44 \times 10^{-2}\right.$ moles $\left./ 800 \mathrm{ml}\right)$ ha experimentado, así mismo, una disminución que depende de la mezcla utilizada en la fabricación de las probetas y del tiempo de conservación-ataque; en la nueva fase sólida se ha encontrado el ión $\mathrm{SO}_{4}$ (II) en cantidades menores de $0,06 \times 10^{-2}$ moles. Cuando los contenidos de escoria de las mezclas mencionadas son elevados (60 y $70 \%$, en peso) los contenidos de $\mathrm{SO}_{4}(\mathrm{II})$ experimentan variaciones minimas.

Por el contrario, en el contenido de Cl (I) en el medio (agua de mar artificial) en donde han estado las probetas de mortero influye, de un modo especial, la cantidad de escoria en la mezcla utilizada para fabricar las series de probetas; el contenido minimo de dichos iones $\mathrm{Cl}$ (I) corresponde al caso de las mezclas que tienen 35 y $60 \%$ de escoria. conditions of the means and, in a special manner, in the concentration of the groups $\mathrm{OH}(\mathrm{I})$. The ion Mg (II) has practically disappeared from the artificial sea water in wich there have been submerged the test speciments of mortar made with cement 1 and with the mixture which has $15 \%$ of slag, in wight; in the remaining means there has been detected the ion $\mathrm{Mg}(\mathrm{II})$ in variable quantities according to the mixture utilized in the preparation of the test speciments. The ion $\mathrm{Mg}$ (II) has been found in the new solid phases formed in the artificial sea water in which there have been submerged the series of test speciments manufactured with cement 1 and with the mixture which has $15 \%$ of slag; it has precipitated as brucite.

The content of $\mathrm{SO}_{4}$ (II) of the artificial sea water $\operatorname{ASTM}\left(2.44 \times 10^{-2}\right.$ mols. $\left./ 800 \mathrm{ml}\right)$ has likewise experienced a decrease which depends on the mixture utilized in the manufacture of the test speciments and on the time of conservation-attack; in the new solid phase there has been found the ion $\mathrm{SO}_{4}$ (II) in quantities less than $0.06 \times 10^{-2}$ mols. When the contents of slag of the mixtures referred to are raised (60 and $70 \%$, in weight) the contents of $\mathrm{SO}_{4}(\mathrm{II})$ experiment minimum variations.

On the contrary, in the content of $\mathrm{Cl}(\mathrm{I})$ in the means, (artificial sea water) in which there have been the test speciments of mortar, there is an influence, in a special manner, of the slag in the mixture utilized to manufacture the series of test speciments; the minimum content of said ions $C l(I)$ corresponds to the case of the mixtures which have 35 and $60 \%$ of slag.

\section{INTRODUCCION}

En otros trabajos anteriores (1) (2) (3) (4) se estudió:

a) La evolución que experimenta la resistencia quimica por el método de Koch-Steinegger y las modificaciones sufridas por las resistencias mecánicas a flexotracción de las probetas de mortero $(1: 3)$ de $1 \times 1 \times 6 \mathrm{~cm}$ hechas con el cemento portland industrial de alta resistencia inicial (cemento $1<>$ P-550-ARI), objeto del presente artículo, y con las mezclas cemento $1 /$ escoria $=85 / 15-65 / 35-40 / 60$ y $30 / 70$, en peso, sumergidas en agua potable filtrada $(*)$, unas series de 12 probetas, y en agua de mar artificial ASTM D 1141-75 (**), otras series análogas, durante $56-90-180$ y 360 dias después de haberlas curado 24 horas en un recinto saturado de humedad y, a continuación, bajo agua potable filtrada hasta 22 dias (1).

b) La composición estructural de las nuevas fases sólidas formadas en los medios de curado y de conservación (agua potable filtrada) (2), así como de conservación-ataque (agua de mar artificial) (3), en donde han estado sumergidas las mencionadas series de probetas de mortero.

c) La evolución de las características estructurales de la fracción enriquecida (cemento hidratado y cemento hidratado-atacado), extraída de uno de los prismas de mortero de cada serie de probetas del sistema cemento 1/escoria-agua potable filtrada (2) y del sistema cemento 1 /escoria-agua de mar artificial (3).

(*) Sistema: cemento 1/escoria-agua potable filtrada.

$\left.{ }^{* *}\right)$ Sistema: cemento 1/escoria-agua de mar artificial. 
d) La variación de la concentración de los iones calcio y sulfato en los medios de curado y de conservación (agua potable filtrada) en donde han estado sumergidas las diversas series de probetas de mortero, así como de las fases sólidas formadas, y la evolución del $\mathrm{pH}$ de dichos medios (4).

En el presente artículo, continuación de los anteriores y que se ampliará con otros, se estudia la variación de la concentración de los iones calcio, magnesio, sulfato y cloruro del agua de mar artificial (ASTM D 1141-75) en donde han estado sumergidas las diversas series de probetas de mortero, así como de las fases sólidas formadas (los tres primeros); asi mismo, se estudia la evolución del $\mathrm{pH}$ de dichos medios y de las cantidades de las mencionadas nuevas fases sólidas.

\section{PARTE EXPERIMENTAL}

Con el fin de conocer la variación del $\mathrm{pH}$, así como de la concentración de los iones calcio, magnesio, sulfato y cloruro del agua de mar artificial (ASTM D 1141-75) en donde han estado sumergidas las probetas de mortero $(1: 3)$, hechas con cemento 1 y con las mezclas cemento $1 /$ escoria $=85 / 15,65 / 35,40 / 60$ y $30 / 70$ (en peso), durante $56,90,180$ y 360 días (periodos de conservación-ataque), se ha determinado el contenido de dichos iones y el valor del $\mathrm{pH}$ en la disolución (agua de mar artificial), una vez separada la nueva fase sólida formada como se señala en (3), que se ha secado en una corriente de nitrógeno. En la nueva fase sólida, puesta en disolución por ataque con una disolución de ácido clorhídrico $(1+1)$, se ha determinado, igualmente, el contenido de los iones calcio, magnesio y sulfato.

El contenido de los iones calcio y magnesio se ha determinado complexométricamente con EDTA, el de los iones sulfato gravimétricamente al estado de sulfato de bario, el de los iones cloruro volumétricamente por el método de Mohr y el valor del $\mathrm{pH}$ por medio de un $\mathrm{pH}$-metro, marca CRISON, modelo 501.

De los materiales utilizados y caracteristicas (cemento 1, escoria, arena, agua de mar artificial y agua potable filtrada), de la técnica operatoria seguida para preparar las mezclas cemento $1 /$ escoria, así como para curar y conservar las probetas de mortero de las diversas series en agua potable filtrada y en agua de mar artificial, respectivamente, se dió cuenta en (1).

\section{RESULTADOS Y DISCUSION}

En la tabla 1 figuran:

a) Las cantidades de las nuevas fases sólidas formadas en las disoluciones (*) (agua de mar artificial ASTM D 1141-75) en donde han estado sumergidas las diversas series de probetas hechas con las mezclas cemento $1 /$ escoria $=100 / 0,85 / 15,65 / 35,40 / 60$ y $30 / 70$ (en peso), durante $56,90,180$ y 360 dias.

b) Los valores del $\mathrm{pH}$ de las mencionadas disoluciones, asi como los contenidos de $\mathrm{Ca}$ (II), $\mathrm{Mg}$ (II), $\mathrm{SO}_{4}$ (II) y $\mathrm{Cl}$ (I).

c) Los contenidos de $\mathrm{Ca}$ (II), $\mathrm{Mg}$ (II) y $\mathrm{SO}_{4}$ (II) en las nuevas fases sólidas.

En las figuras 1 a 11 se han representado dichos valores en función del tiempo de conservaciónataque o de la mezcla utilizada para preparar las diversas series de probetas de mortero, que se discuten en los apartados siguientes.

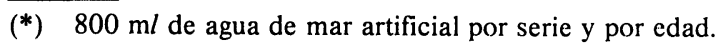


T ABLA 1

Sistema: cemento 1/escoria-agua de mar artificial ASTM

Evolución de la fase sólida formada, del pH y de los contenidos de Ca(II), $\mathrm{Mg}$ (II), $\mathrm{SO}_{4}(\mathrm{II})$ y Cl(I)

Agua de mar ASTM (D 1141-75): Ca (II) $=1,04 \times 10^{-2}$ moles $/ 800 \mathrm{ml}$;

$M g(I I)=4,43 \times 10^{-2}$ moles $/ 800 \mathrm{ml} ; \mathrm{SO}_{4}(\mathrm{II})=2,44 \times 10^{-2} \mathrm{moles} / 800 \mathrm{ml}$;

$\mathrm{Cl}(\mathrm{I})=44,2 \times 10^{-2}$ moles $/ 800 \mathrm{ml} ; \mathrm{pH}=6,5$

\begin{tabular}{|c|c|c|c|c|c|c|c|c|c|c|c|c|c|c|}
\hline \multirow{2}{*}{$\begin{array}{l}\text { Mezcla: } \\
\text { cemento 1 }\end{array}$} & \multirow{2}{*}{$\begin{array}{l}\text { Edad } \\
\text { dias }\end{array}$} & \multicolumn{2}{|c|}{ Fase sólida } & \multirow{2}{*}{$\begin{array}{c}\text { Diso- } \\
\text { lución } \\
\text { pH }\end{array}$} & \multicolumn{3}{|c|}{ Ca (II); moles $\times 10^{-2}$} & \multicolumn{3}{|c|}{ Mg (II); moles $\times 10^{-2}$} & \multicolumn{3}{|c|}{$\mathrm{SO}_{4}(\mathrm{II}) ;$ moles $\times 10^{-2}$} & \multirow{2}{*}{ 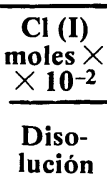 } \\
\hline & & g & DRX & & $\begin{array}{l}\text { Diso- } \\
\text { lución }\end{array}$ & $\begin{array}{l}\text { Fase } \\
\text { solida }\end{array}$ & Suma & $\begin{array}{l}\text { Diso- } \\
\text { lución }\end{array}$ & $\begin{array}{l}\text { Fase } \\
\text { sólida }\end{array}$ & Suma & $\begin{array}{l}\text { Diso- } \\
\text { lución }\end{array}$ & $\begin{array}{l}\text { Fase } \\
\text { sólida }\end{array}$ & Suma & \\
\hline \multirow{4}{*}{$100 / 0$} & 56 & 1,73 & $\mathrm{C} c^{\top}-\mathrm{Ag}-\mathrm{B}$ & 11,7 & 3,41 & 1,35 & 4,76 & 0,10 & 0,31 & 0,41 & 1,34 & 0,04 & 1,38 & 43,0 \\
\hline & 90 & 2,35 & $\mathrm{Cc} c^{\uparrow}-\mathrm{Ag}-\mathrm{B}$ & 7,6 & 3,36 & 1,87 & 5,23 & 0,14 & 0,31 & 0,45 & 1,31 & 0,03 & 1,34 & 44,0 \\
\hline & 180 & 2,32 & $\mathrm{Cc}^{\dagger}-\mathrm{Ag}-\mathrm{B}^{\dagger}$ & 12,0 & 3,90 & 1,57 & 5,47 & n.d. & 0,80 & 0,80 & 1,00 & 0,04 & 1,04 & 44,1 \\
\hline & 360 & 3,94 & $\mathrm{C} c^{\top}-\mathrm{Ag}-\mathrm{B}$ & 11,5 & 3,15 & 3,59 & 6,74 & n.d. & 0,21 & 0,21 & 0,68 & 0,03 & 0,71 & 44,2 \\
\hline \multirow{4}{*}{$85 / 15$} & 56 & 1,42 & $\mathrm{Cc}-\mathrm{Ag}-\mathrm{B}$ & 10,6 & 3,01 & 1,12 & 4,13 & 0,15 & 0,20 & 0,35 & 1,33 & 0,03 & 1,36 & 42,3 \\
\hline & 90 & 1,74 & $\mathrm{Cc}^{\mathrm{i}-} \quad-\mathrm{B}$ & 10,8 & 3,13 & 1,37 & 4,50 & n.d. & 0,31 & 0,31 & 1,26 & 0,03 & 1,29 & 41,6 \\
\hline & 180 & 0,97 & $\mathrm{Cc}^{\dagger}-\mathrm{Ag}-\mathrm{B}$ & 11,8 & 3,31 & 0,82 & 4,13 & n.d. & ind. & ind. & 1,00 & 0,01 & 1,01 & 43,3 \\
\hline & 360 & 3,62 & $\mathrm{Cc}^{\dagger}-\mathrm{Ag}-\mathrm{B}$ & 9,7 & 2,46 & 3,19 & 5,65 & n.d. & 0,39 & 0,39 & 0,56 & 0,05 & 0,61 & 44,1 \\
\hline \multirow{4}{*}{$65 / 35$} & 56 & 0,39 & $\mathrm{Cc}-\mathrm{Ag}$ & 7,7 & 2,54 & 0,35 & 2,89 & 0,18 & n.d. & 0,18 & 1,59 & $0,00_{6}$ & 1,60 & 41,0 \\
\hline & 90 & 0,77 & $\mathrm{Cc}-\mathrm{Ag}$ & 7,8 & 2,54 & 0,62 & 3,16 & 0,14 & n.d. & 0,14 & 1,42 & 0,03 & 1,45 & 40.9 \\
\hline & 180 & 1,22 & $\mathrm{Cc}^{\mathrm{T}}-\mathrm{Ag}$ & 7,7 & 2,51 & 1,15 & 3,66 & 0,08 & n.d. & 0,08 & 1,34 & 0,02 & 1,36 & 42,2 \\
\hline & 360 & 2,00 & $\mathrm{Cc}^{\mathrm{t}}-\mathrm{Ag}$ & 7,5 & 2,35 & 1,95 & 4,30 & 0,11 & n.d. & 0,11 & 1,14 & 0,01 & 1,15 & 44,1 \\
\hline \multirow{4}{*}{$40 / 60$} & 56 & 0,49 & $\mathrm{Cc}-\mathrm{Ag}^{\dagger}-\mathrm{Y}$ & 7,8 & 1,47 & 0,35 & 1,82 & 2,05 & n.d. & 2,05 & 2,06 & $0,00_{5}$ & 2,07 & 41,6 \\
\hline & 90 & 0,51 & $\mathrm{Cc}-\mathrm{Ag}^{\uparrow}$ & 7.8 & 1,49 & 0,40 & 1,89 & 1,76 & n.d. & 1,76 & 2,02 & $0,00_{4}$ & 2,02 & 40,9 \\
\hline & 180 & 0,59 & $\mathrm{Cc}-\mathrm{Ag}^{\uparrow}$ & 7,8 & 1,63 & 0,55 & 2,18 & 1,39 & n.d. & 1,39 & 1,93 & $0,00_{5}$ & 1,94 & 42,0 \\
\hline & 360 & 1,31 & $\mathrm{Cc}-\mathrm{Ag}$ & 7,9 & 1,44 & 1,15 & 2,59 & 1,68 & n.d. & 1,68 & 1,95 & $0,00_{7}$ & 1,96 & 43,7 \\
\hline \multirow{4}{*}{$30 / 70$} & 56 & 0,43 & $\mathrm{Cc}-\mathrm{Ag}^{\top}$ & 7,8 & 1,23 & 0,37 & 1,60 & 2,83 & n.d. & 2,83 & 2,30 & $0,00_{4}$ & 2,30 & 42,0 \\
\hline & 90 & 0,49 & $\mathrm{Cc}-\mathrm{Ag}^{\top}$ & 7,8 & 1,71 & 0,42 & 2,13 & 2,06 & n.d. & 2,06 & 2,19 & $0,00_{4}$ & 2,19 & 41.6 \\
\hline & 180 & 0,59 & $\mathrm{Cc}-\mathrm{Ag}^{\uparrow}$ & 7,9 & 1,34 & 0,52 & 1,86 & 2,35 & n.d. & 2,35 & 2,21 & $0,00_{4}$ & 2,21 & 42,2 \\
\hline & 360 & 0,77 & $\mathrm{Ag}$ & 7,9 & 1,12 & 0,67 & 1,79 & 2,59 & n.d. & 2,59 & 2,26 & $0,00_{5}$ & 2,27 & 44,1 \\
\hline
\end{tabular}

n.d. $=$ no detectado $\mathrm{Cc}=$ Calcita $\mathrm{Ag}=$ Aragonito $\mathrm{B}=$ Brucita $; \mathrm{Y}=$ Yeso

\subsection{Evolución de la cantidad de fase sólida}

En las figuras 1 y 2 se ha representado la evolución de las cantidades de las fases sólidas formadas, en las disoluciones mencionadas anteriormente, para las series de probetas hechas con una misma mezcla en función del tiempo de conservación-ataque, en la primera, y para cada edad en función de la mezcla utilizada para fabricar las diversas series de probetas, en la segunda, en donde se observa que dicha cantidad de fase sólida es función:

a) Del tiempo de conservación-ataque, para cada mezcla, produciéndose un incremento considerable en las fases sólidas formadas en los medios en donde han estado sumergidas durante 360 días, con relación a 56 dias, las series de probetas hechas con cemento 1 y con 


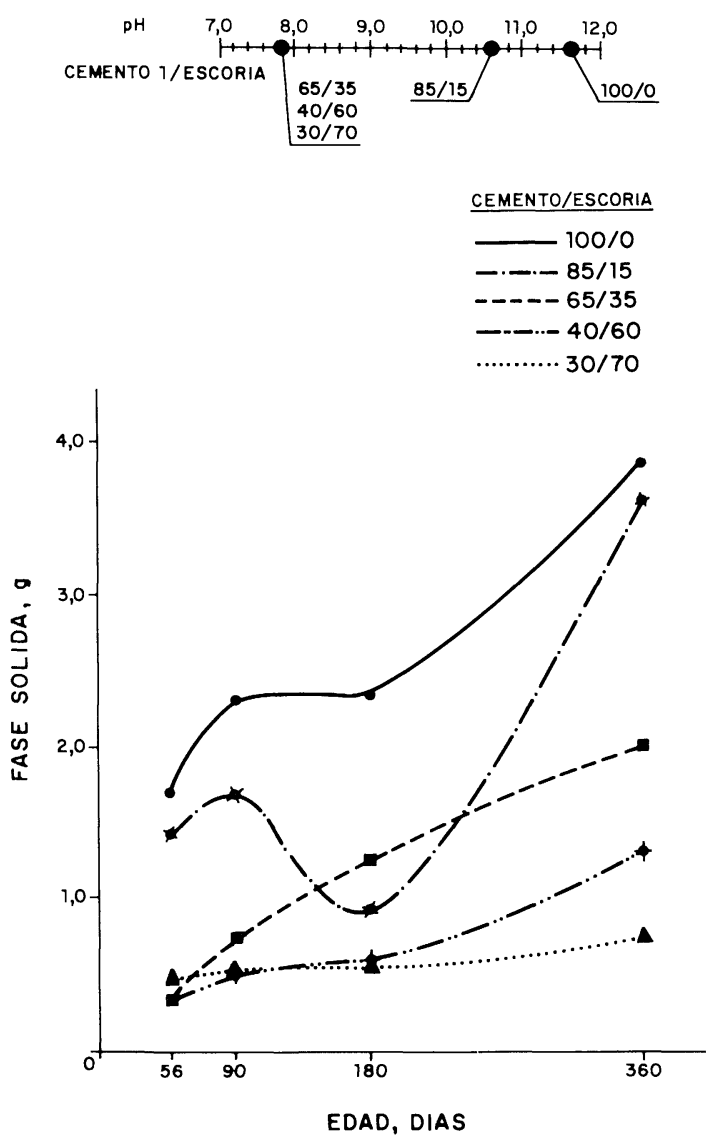

Fig. 1.-Sistema: cemento 1/escoria-agua de mar artificial ASTM.

Evolución de la cantidad de fase sólida y del $\mathrm{pH}$.

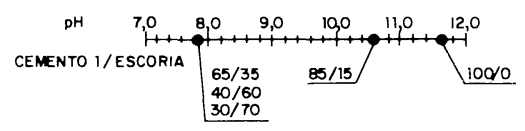

EDAD, DIAS

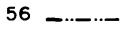

$90----$

180 -...-

360

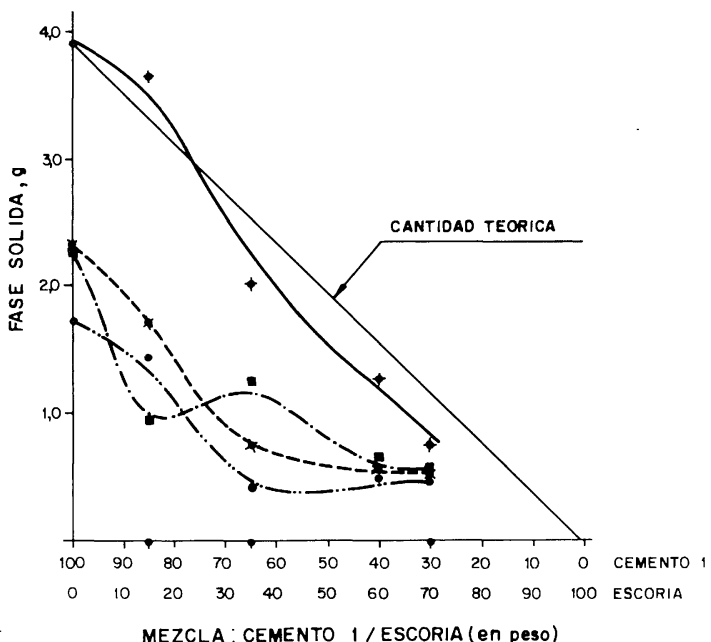

Fig. 2.-Sistema: cemento 1/escoria-agua de mar artificial ASTM.

Evolución de la cantidad de fase sólida y del pH.

la mezcla que tiene $15 \%$ de escoria, pasando de $1,73 \mathrm{~g}$ a $3,94 \mathrm{~g}$, en el primer caso, y de $1,42 \mathrm{~g}$ a $3,62 \mathrm{~g}$, en el segundo caso (figura 1). Este incremento es mínimo cuando se trata de las disoluciones en donde han estado sumergidas las series de probetas elaboradas con las mezclas cemento $1 /$ escoria $=40 / 60$ y $30 / 70$ (en peso).

b) De la mezcla utilizada, para cada edad, produciéndose una disminución conforme se incrementa la cantidad de escoria, o disminuye la de cemento, en la mezcla utilizada para fabricar las diversas series de probetas (figura 2). En esta figura se aprecia que la cantidad de fase sólida formada en las cinco series sumergidas durante 360 días, responde prácticamente a la cantidad teórica, calculada a partir de la fase sólida formada en el medio en donde han estado las probetas hechas con cemento 1 .

En las fases sólidas mencionadas se han identificado por difracción de rayos $\mathrm{X}$ (3) los picos de los siguientes compuestos cristalinos: brucita, $\mathrm{Mg}(\mathrm{OH})_{2}$; calcita, $\mathrm{CaCO}_{3}$, y aragonito, $\mathrm{CaCO}_{3}$. Los picos del yeso - $\mathrm{CaSO}_{4} \cdot 2 \mathrm{H}_{2} \mathrm{O}$ - de pequeña intensidad, únicamente, se han detectado en el DRX de la fase sólida formada en el caso cemento 1/escoria (40/60)-agua de mar artificial (56 días).

Los picos de la calcita, asi como los del aragonito, se han detectado en todos los DRX, excepto en los correspondientes a los medios en donde han estado sumergidas las series de probetas hechas con la mezcla cemento $1 /$ escoria $=30 / 70$ (en peso) durante 360 dias, para la calcita, y $85 / 15$ (en peso) durante 90 días, para el aragonito.

Los picos de la brucita se han puesto de manifiesto en los diagramas de difracción de rayos $\mathrm{X}$ 
de las fases sólidas formadas en el agua de mar artificial en donde han estado sumergidas, durante las cuatro edades, las series de probetas hechas con cemento 1 y con la mezcla que tiene la menor cantidad de escoria (15\%).

La máxima intensidad de los picos de la calcita, análoga entre sí, es la correspondiente a los DRX de las fases sólidas formadas en los medios de conservación-ataque (agua de mar artificial) en donde han estado sumergidas, durante las cuatro edades, las series de probetas fabricadas con las mezclas cemento $1 /$ escoria $=100 / 0$ y $85 / 15$ (en peso) y la mínima intensidad, para todas las edades, corresponde a los diagramas de la fase sólida que aparece en el agua de mar artificial en donde se sumergieron las series de probetas elaboradas con las mezclas cemento $1 /$ escoria que tienen los mayores contenidos de escoria (60 y $70 \%$, en peso). Por el contrario, la máxima intensidad de los picos del aragonito corresponde a los DRX que presentan la minima en la calcita y a la inversa; es decir, la minima intensidad de los picos del aragonito se corresponde con los casos de máxima intensidad en los picos de la calcita.

Para el caso cemento 1/escoria (65/35)-agua de mar artificial, la intensidad de los picos mencionados, tanto de la calcita como del aragonito, es intermedia a la de los restantes casos estudiados.

\subsection{Evolución del $\mathbf{p H}$}

Por regla general, el valor del $\mathrm{pH}$ en donde han estado sumergidas las cuatro series de probetas de morteros hechas con las mezclas cemento 1 escoria $=100 / 0$ y $85 / 15$ (en peso) es superior a 10 e igual o inferior a 12,0 y el correspondiente a las restantes series es igual o superior a 7,5 e inferior a 8,0 .

El pH del agua de mar artificial ASTM D 114175 es 6,5 .

\subsection{Evolución del contenido de Ca (II)}

En las figuras 3 y 4 se ha representado la evolución del contenido de $\mathrm{Ca}$ (II) [Ca (II) en la fase sólida $+\mathrm{Ca}$ (II) en la fase disuelta] procedente, de un modo especial, del $\mathrm{Ca}(\mathrm{OH})_{2}$ disuelto del cemento hidratado en función del tiempo de conservación-ataque para cada conjunto de series de probetas de mortero fabricadas con una mezcla cemento 1 /escoria, primera figura, y de la mezcla utilizada en dicha fabricación, para cada edad, segunda figura.

En la figura 3 se aprecia que la cantidad del mencionado $\mathrm{Ca}$ (II), para cada mezcla, aumenta con el tiempo de conservación-ataque; experimentando las diversas series de probetas sumergidas durante 56 y 360 días los incrementos que se encuentran en la tabla 2.

En la figura 4 se observa que, para cada edad, la cantidad de $\mathrm{Ca}$ (II) $<>\mathrm{Ca}(\mathrm{OH})_{2}$ disuelto, que se encuentra en la disolución y en la fase solida, disminuye bruscamente conforme lo hace



Fig. 3.-Sistema: cemento 1/escoria-agua de mar artificial ASTM.

Evolución del contenido de Ca (II) disuelto. 
el contenido de cemento 1 , o aumenta el de escoria, en la mezcla utilizada para fabricar las diversas series de probetas de mortero. $\mathrm{Si}$, además, del mencionado $\mathrm{Ca}$ (II) se considera el $\mathrm{Ca}$ (II) que corresponde al agua de mar artificial ASTM $\left(1,04 \times 10^{-2}\right.$ moles $\left./ 800 \mathrm{ml}\right)$, es decir, el Ca (II) total que existe en la disolución y el Ca (II) que se encuentra en la nueva fase sólida (figura 5), se aprecia que, para cada edad, dichas cantidades se encuentran alineadas, prácticamente, en una recta que une los puntos correspondientes al $\mathrm{Ca}(\mathrm{OH})_{2}$ disuelto de las series de probetas hechas con cemento 1, más el del agua de mar, en ordenadas, y el de la mezcla teórica cemento $1 /$ escoria $=0 / 100$, es decir cuando no existe cemento 1 , en abscisas; se trata, por consiguiente, de un fenómeno aditivo.

T ABLA 2

Sistema: cemento 1/escoria-agua de mar artificial ASTM

Evolución del contenido de Ca (II) en la disolución y en la fase sólida, en moles $\times 10^{-2}$

\begin{tabular}{|c|c|c|c|c|}
\hline \multirow{2}{*}{ Mezcoria } & \multicolumn{2}{|c|}{ Ca (II) disuelto; moles $\times 10^{-2}$} & \multirow{2}{*}{$\Delta$} & \multirow{2}{*}{$\%$} \\
\hline & 56 días & 360 dias & & \\
\hline $100 / 0$ & 3,72 & 5,70 & 1,98 & 53,2 \\
\hline $85 / 15$ & 3,09 & 4,61 & 1,52 & 49,2 \\
\hline $65 / 35$ & 1,85 & 3,26 & 1,41 & 76,2 \\
\hline $40 / 60$ & 0,78 & 1,56 & 0,77 & 98,7 \\
\hline $30 / 70$ & 0,56 & 0,75 & 0,19 & 33,9 \\
\hline
\end{tabular}

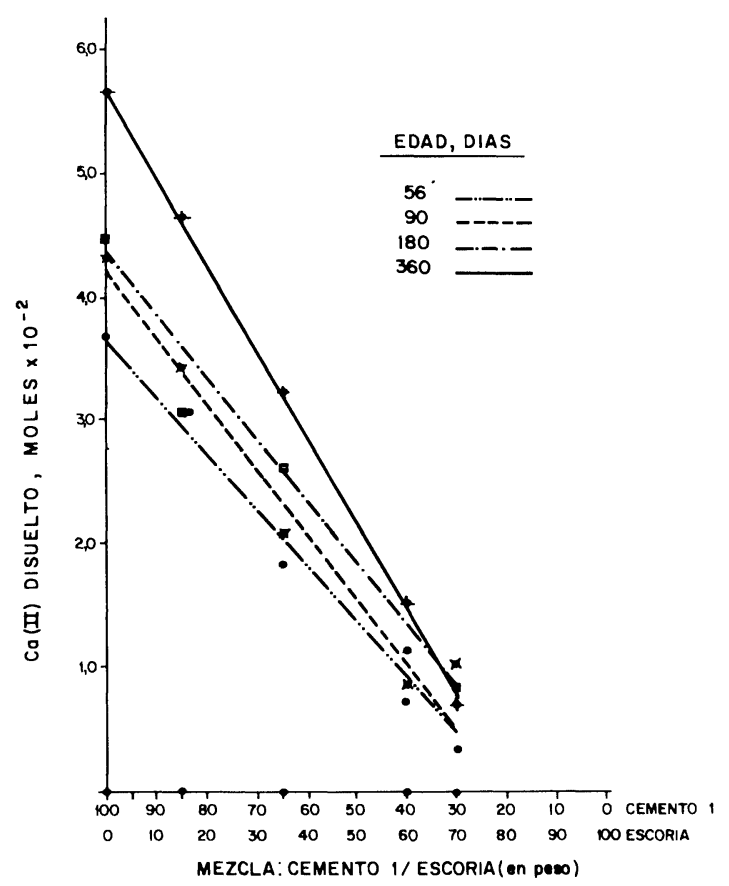

Fig. 4.-Sistema: cemento 1/escoria-agua de mar artificial ASTM.

Evolución del contenido de Ca (II) disuelto.

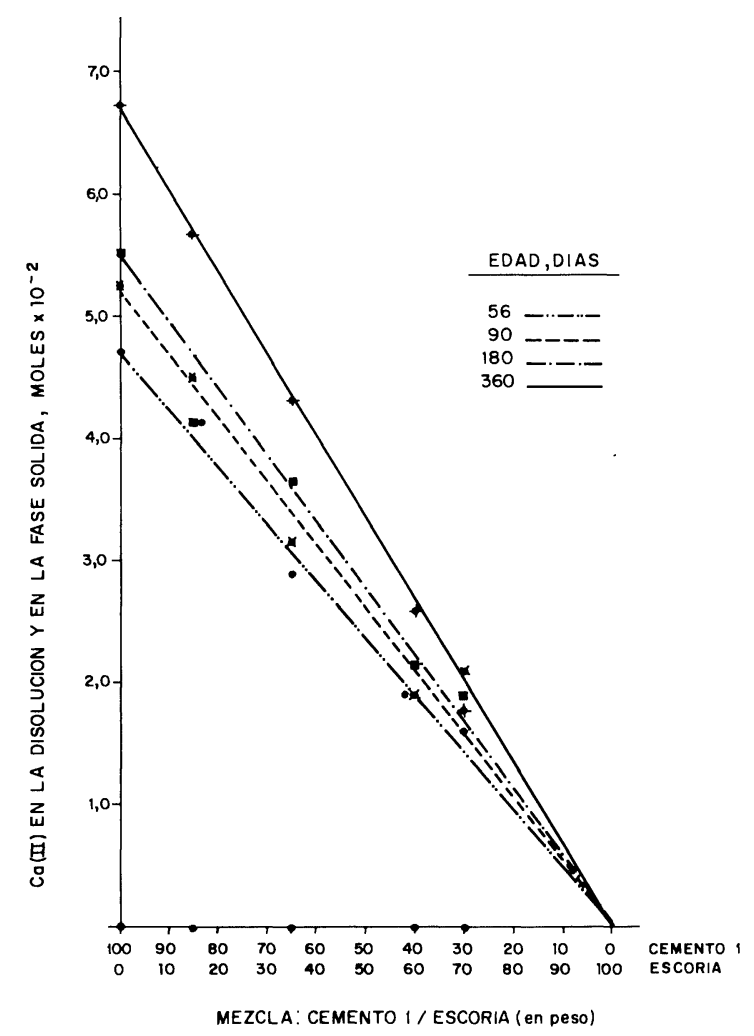

Fig. 5.-Sistema: cemento 1/escoria-agua de mar artificial ASTM.

Evolución del contenido de Ca (II) total. 


\subsection{Evolución del contenido de $\mathrm{Mg}$ (II)}

En las figuras 6 y 7 se ha representado el contenido de $\mathrm{Mg}$ (II) en el agua de mar artificial (ASTM D 1141-75), en donde han estado sumergidas las diversas series de probetas de mortero, junto con el de la nueva fase sólida que se ha formado en dichos medios, en función de la edad (primera figura) y de la mezcla cemento 1/escoria utilizada para fabricar dichas series de probetas (segunda figura).

El contenido de $\mathrm{Mg}$ (II) del agua de mar artificial ASTM $\left(4,43 \times 10^{-2}\right.$ moles $\left./ 800 \mathrm{~m} l\right)$ experimenta, en todos los casos estudiados, una disminución que es función del tiempo de conservación-ataque y de la mezcla utilizada en la fabricación de las diversas series de probetas de mortero (tabla 1; figuras 6 y 7), que influye en las condiciones del medio, modificando, de un modo especial, la concentración de grupos $\mathrm{OH}(\mathrm{I})$, es decir, el valor del $\mathrm{pH}$.

El ion $\mathrm{Mg}$ (II) ha desaparecido, prácticamente, de los medios (agua de mar artificial ASTM) en donde han estado sumergidas las series de probetas de mortero hechas con cemento $1 \mathrm{y}$ con la mezcla cemento $1 /$ escoria $=85 / 15$ (en peso), no habiéndose detectado en los correspondientes a las edades de $22+180$ y $22+360$ días para ambas mezclas y $22+90$ días para la segunda; en los medios restantes se ha detectado dicho ion en cantidades inferiores a $0,15 \times 10^{-2}$ moles. Por el contrario, dicho ion magnesio se ha detectado en cantidades superiores a $1,3 \times 10^{-2}$ moles en el agua de mar artificial ASTM en donde han estado las series de probetas hechas con cemento $1 /$ escoria $=40 / 60$ y $30 / 70$ (en peso) y en cantidades comprendidas entre $0,08 \times 10^{-2}$ y $0,18 \times 10^{-2}$ moles en los medios de las probetas elaboradas con la mezcla cemento $1 /$ escoria $=65 / 35$ (en peso).

Por otra parte, el ion Mg (II) se ha encontrado en las nuevas fases sólidas formadas en el agua de mar artificial en donde han estado sumergidas las series de probetas fabricadas con cemento 1 y con la mezcla que tiene el menor contenido de escoria (15\%), en cantidades comprendidas entre $0,20 \times 10^{-2}$ y $0,80 \times 10^{-2}$ moles; dicho ion ha precipitado como $\left.\mathrm{MgOH}\right)_{2}$, en forma de brucita.

En las fracciones enriquecidas extraídas de todas las series de probetas fabricadas con las mezclas cemento 1/escoria, sumergidas durante 56 - 90 - 180 y 360 días en agua de mar artificial ASTM, se ha detectado por DRX (3) el compuesto cristalino brucita.

En la figura 6 se observa que la evolución de los contenidos de $\mathrm{Mg}$ (II) de las disoluciones, más los de las nuevas fases sólidas, en donde han estado sumergidas las series de probetas de mortero hechas con las mezclas cemento $1 /$ escoria $=85 / 15,40 / 60$ y 30/70 (en peso) siguen una evolución con un hábito parecido, a lo largo del tiempo, aun cuando las cantidades de dicho ion son menores conforme es mayor el contenido de cemento 1 en las mencionadas mezclas.

Las menores cantidades de $\mathrm{Mg}$ (II), en la disolución más en la nueva fase sólida, corresponden a los medios en donde han estado las cuatro series de probetas de mortero hechas con la mezcla cemento 1 escoria $=65 / 35$ (en peso).

En los medios donde han estado las series de probetas fabricadas con cemento 1, las cantidades de dicho ion $\mathrm{Mg}$ (II) son inferiores a las de los sistemas parciales cemento 1/escoria (40/60 y $30 / 70$, en peso)-agua de mar artificial y superiores o del mismo orden a las de los otros dos sistemas parciales.

Las cantidades de $\mathrm{Mg}$ (II) en la disolución, más en la fase sólida, siguen una evolución análoga (figura 7), de tal modo que para las disoluciones (agua de mar artificial) en donde han estado sumergidas las series de probetas elaboradas con las mezclas cemento $1 /$ escoria $=100 / 0,85 / 15$ y 65/35 (en peso), para las cuatro edades estudiadas por el momento, los contenidos de dicho 


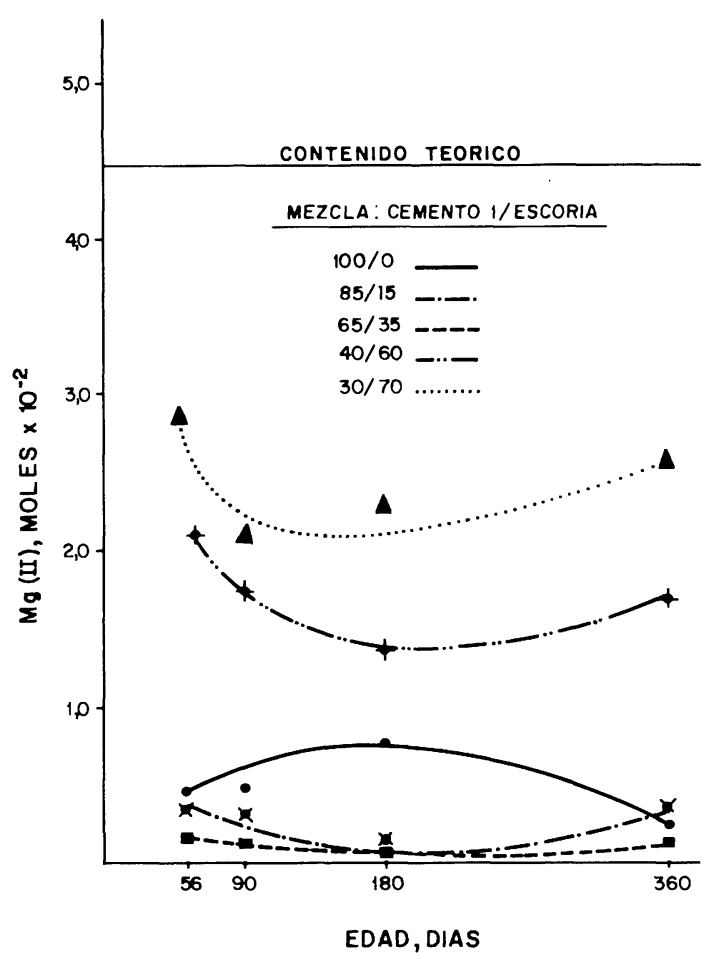

Fig. 6.-Sistema: cemento 1/escoria-agua de mar artificial ASTM

Evolución del contenido de $\mathrm{Mg}$ (II) en la disolución más en la fase sólida.

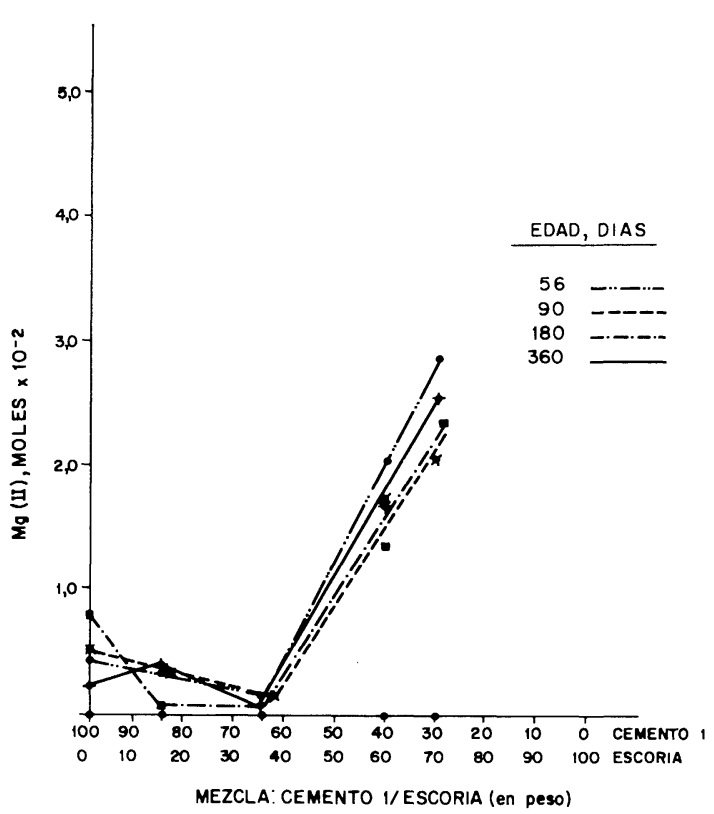

Fig. 7.-Sistema: cemento 1/escoria-agua de mar artificial ASTM.

Evolución del contenido de $\mathrm{Mg}$ (II) en la disolución más en la fase sólida.

ion $\mathrm{Mg}$ (II) son menores de $0,9 \times 10^{-2}$ moles y superiores a $1,3 \times 10^{-2}$ moles e inferiores a $2,85 \times 10^{-2}$ moles en los dos casos restantes; es decir, en los medios en donde se han conservado-atacado las series de probetas hechas con las mezclas que tienen los mayores contenidos de escoria (60 y $70 \%$, en peso). Por el contrario, el $\mathrm{Mg}$ (II) que ha desaparecido del agua de mar y que no ha precipitado en la nueva fase sólida, es mayor de $3,53 \times 10^{-2}$ moles, en los tres primeros casos, e inferior a $3,13 \times 10^{-2}$ moles y superior a $1,58 \times 10^{-2}$ moles en los otros dos casos.

\subsection{Evolución del contenido de $\mathrm{SO}_{4}$ (II)}

El contenido de $\mathrm{SO}_{4}$ (II) en el agua de mar artificial ASTM D 1141-75 $\left(2,44 \times 10^{-2}\right.$ moles/800 $\mathrm{m} l$ ) ha experimentado, en todos los casos estudiados, una disminución que depende del tiempo de conservación-ataque de la mezcla cemento 1/escoria utilizada en la fabricación de las diversas series de probetas de mortero (tabla 1, figuras 8 y 9). Los iones $\mathrm{SO}_{4}$ (II) se han detectado en el agua de mar artificial en cantidades comprendidas entre $0,56 \times 10^{-2}$ moles y $2,30 \times 10^{-2}$ moles y en la nueva fase sólida en cantidades menores de $0,06 \times 10^{-2}$ moles; prácticamente, dicho iones $\mathrm{SO}_{4}$ (II) se encuentran, en estos casos, en la disolución.

En las fracciones enriquecidas extraidas de todas las séries de probetas fabricadas con las distintas mezclas cemento 1/escoria, que se han sumergido en la mencionada agua de mar ASTM durante las edades reseñadas anteriormente, se han detectado por DRX los compuestos cristalinos ettringita y yeso secundario (3); la intensidad de los picos de dichos compuestos depende de la mezcla utilizada en la fabricación de las probetas de mortero.

En las figuras 8 y 9 se ha representado la evolución del contenido de sulfatos, en la disolución y en la nueva fase sólida, en función del tiempo de conservación-ataque para cada mezcla, en la 


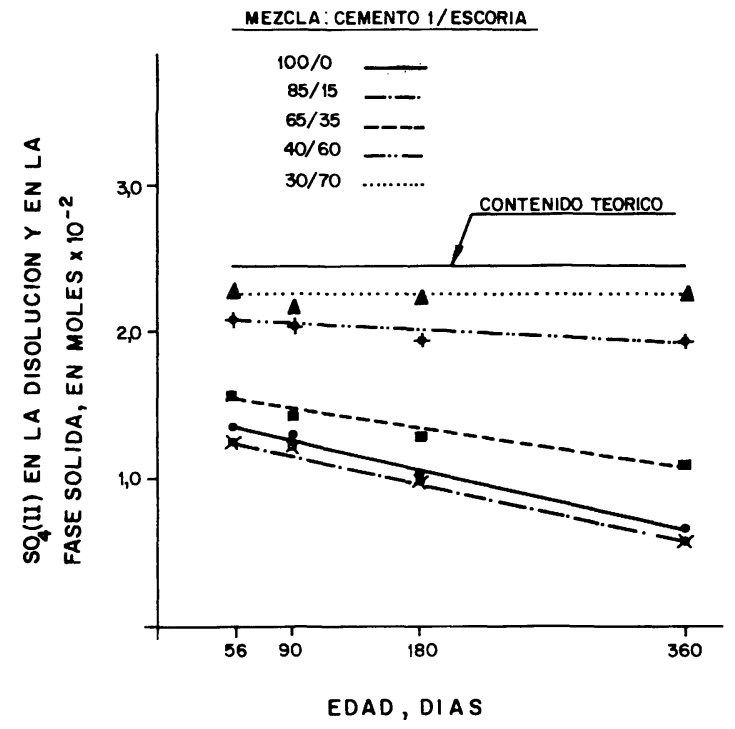

Fig. 8.-Sistema: cemento 1/escoria-agua de mar artificial ASTM.

Evolución del contenido de $\mathrm{SO}_{4}$ (II) en la disolución más en la fase sólida.

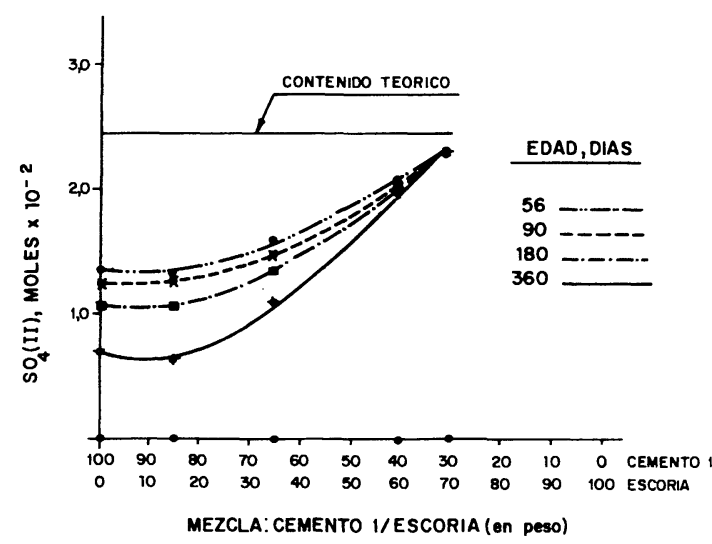

Fig. 9.-Sistema: cemento 1/escoria-agua de mar artificial ASTM.

Evolución del contenido de $\mathrm{SO}_{4}$ (II) en la disolución más en la fase sólida.

primera figura, y de la mezcla utilizada en la elaboración de las probetas de mortero para cada edad, en la segunda figura. En dichas figuras se aprecia:

a) Que el contenido de iones $\mathrm{SO}_{4}$ (II) para los medios (agua de mar artificial) en donde han estado sumergidas las series de probetas hechas con las mezclas que tienen las mayores cantidades de escoria (60 y $70 \%$, en peso) permanece, prácticamente, constante.

Por el contrario, en los tres casos restantes disminuye conforme aumenta el tiempo de conserservación-ataque (figura 8).

b) Que la cantidad de $\mathrm{SO}_{4}$ (II) para cada edad, en la disolución más en la nueva fase sólida, es función de la mezcla cemento 1/escoria empleada en la fabricación de las probetas de mortero, existiendo una disminución de dicho contenido conforme aumenta el tiempo de conservación-ataque en el caso de los medios en donde han estado las series de probetas hechas con cemento 1 y con las mezclas que tienen 15 y $35 \%$ de escoria, en peso; en los dos casos restantes, prácticamente, no existe variación del mencionado contenido de $\mathrm{SO}_{4}$ (II), figura 9.

c) En resumen, que las cantidades desaparecidas de iones $\mathrm{SO}_{4}$ (II) en el agua de mar, fijados por las probetas de mortero formando los compuestos correspondientes, depende de la mezcla cemento 1/escoria utilizada para fabricar las diversas series de probetas de mortero y del tiempo de conservación-ataque.

Cuando los contenidos de escoria de la mezcla son altos (60 y $70 \%$, en peso), las cantidades de $\mathrm{SO}_{4}$ (II) fijadas por las probetas de mortero son las menores $\left(\sim 0,44 \times 10^{-2}\right.$ moles $)$, mientras que cuando se trata de las probetas hechas con cemento 1 ó con las mezclas que tienen 15 y $35 \%$ de escoria llegan a fijarse cantidades del orden de $1,8 \times 10^{-2}$ moles, quedando en la disolución aproximadamente $0,6 \times 10^{-2}$ moles y en la nueva fase sólida $0,05 \times 10^{-2}$ moles.

\subsection{Evolución del contenido de $\mathbf{C l}$ (I)}

Las cantidades de iones cloruro en el agua de mar artificial ASTM en donde han estado 


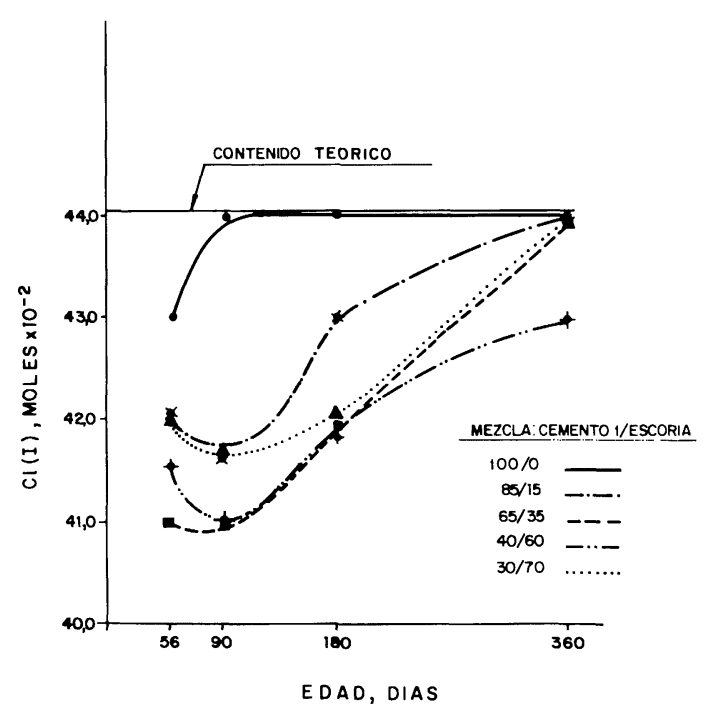

Fig. 10.-Sistema: cemento 1/escoria-agua de mar artificial ASTM.

Evolución del contenido de $\mathrm{Cl}$ (I) en la disolución.

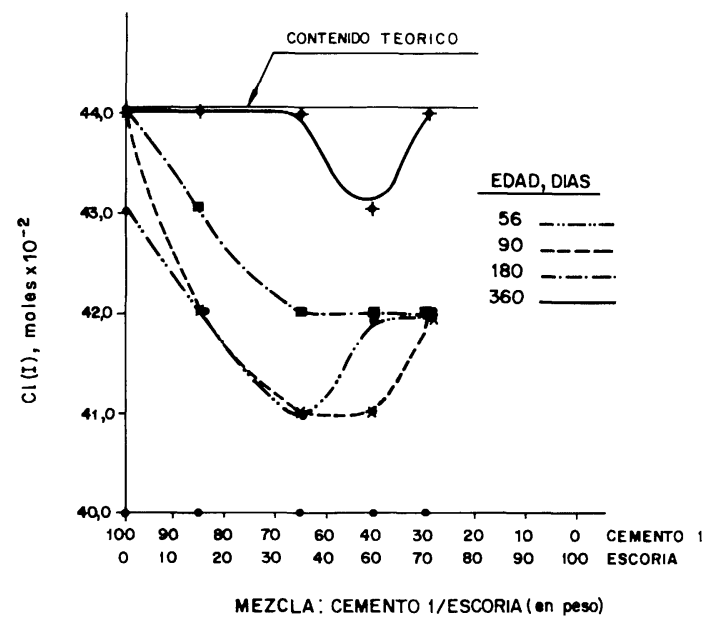

Fig. 11.-Sistema: cemento 1/escoria-agua de mar artificial ASTM.

Evolución del contenido de $\mathrm{Cl}$ (I) en la disolución.

sumergidas las diversas series de probetas de mortero $(1: 3)$ son las que figuran en la tabla 1 , que se han representado en función del tiempo de conservación-ataque (fig. 10) y de la mezcla utilizada para fabricar las mencionadas series de probetas de mortero (fig. 11).

El mencionado contenido de $\mathrm{Cl}$ (I) es función de la mezcla cemento 1/escoria utilizada en la fabricación de las series de probetas de mortero $(1: 3)$ y del tiempo de conservación-ataque (figuras 10 y 11). Las cantidades mayores, aproximadamente del mismo orden que el contenido del agua de mar artificial ASTM $\left(55,2 \times 10^{-2}\right.$ moles/litro $<>44,2 \times 10^{-2}$ moles en $\left.800 \mathrm{ml}\right)$, se presentan en los medios en donde han estado sumergidas las series de probetas hechas con cemento 1 y las menores en el agua de mar artificial que corresponde a las series de probetas elaboradas con las mezclas que tienen 35 y $60 \%$ de escoria, en peso.

A la edad de 360 días el mencionado contenido de dichos iones $\mathrm{Cl}$ (I) es el mayor para los diversos casos estudiados de este sistema.

En la fracción enriquecida, extraida de una probeta de cada serie, sumergida en agua de mar artificial ASTM durante los períodos de tiempo reseñados, se identificaron por difracción de rayos X, entre otros, los picos de la sal de Friedel (3) con intensidades variables según la mezcla utilizada en la elaboración de dichas series de probetas y el tiempo de conservaciónataque. Así, la máxima intensidad corresponde a los DRX de las series de probetas hechas con la mezcla cemento $1 /$ escoria $=65 / 35 \%$ (en peso), a todas las edades, siguiéndole los de la mezcla que tiene $60 \%$ de escoria, y la mínima intensidad a la fracción enriquecida extraída de las probetas hechas con cemento 1 junto con las elaboradas con la mezcla que tiene el menor contenido de escoria (15\%); por otra parte, dicha intensidad disminuye en los diferentes DRX de las muestras extraidas de las probetas sumergidas durante 360 días en la mencionada agua de mar artificial ASTM.

Como puede observarse, estos hechos corresponden, en gran parte, con la eliminación de iones $\mathrm{Cl}$ (I) en el agua de mar artificial ASTM.

\section{INTERPRETACION DE RESULTADOS}

En el medio (agua de mar artificial ASTM D 1141-75) del sistema cemento 1/escoria-agua de 
mar artificial ASTM, en donde han estado sumergidas las diversas series de probetas de mortero hechas con las mezclas cemento 1 /escoria $=100 / 0-85 / 15-65 / 35-40 / 60$ y $30 / 70$ (en peso), se producen una serie de fenómenos, de los que se han estudiado los siguientes, como son: formación de una fase sólida, incremento del $\mathrm{pH}$ y de la cantidad de $\mathrm{Ca}$ (II), disminución del contenido de $\mathrm{Mg}$ (II), de $\mathrm{SO}_{4}$ (II) y de $\mathrm{Cl}$ (I).

El incremento de $\mathrm{Ca}$ (II), con relación al contenido de dicho ion en el agua de mar artificial es producido, fundamentalmente, por la disolución de parte del $\mathrm{Ca}(\mathrm{OH})_{2}$ formado en las probetas de mortero, como consecuencia de las reacciones de hidratación de los compuestos del cemento $\left(\mathrm{C}_{3} \mathrm{~S}, \mathrm{C}_{2} \mathrm{~S}\right.$ y $\mathrm{CaO}$ libre $)$, según la reacción $(\mathrm{A})$ :

$$
\mathrm{Ca}(\mathrm{OH})_{2} \text {. sólido } \stackrel{\mathrm{H}_{2} \mathrm{O} \text { mar }}{\rightleftarrows} \mathrm{Ca}(\mathrm{OH})_{2} \text {.disuelto } \stackrel{\mathrm{H}_{2} \mathrm{O} \text { mar }}{\Longleftrightarrow} \mathrm{Ca}(\mathrm{II})+2 \mathrm{OH}(\mathrm{I})
$$

dando lugar, además, a un incremento de los grupos $\mathrm{OH}$ (I) y, por tanto, del valor del pH, llegando a alcanzar valores de 12,0 .

La solubilidad, a $20^{\circ} \mathrm{C}$, del $\mathrm{Ca}(\mathrm{OH})_{2}$ en agua es $1,230 \mathrm{~g} / \mathrm{l}(5)<>1,66 \times 10^{-2} \mathrm{moles} / \mathrm{li}$ tro $<>1,33 \times 10^{-2}$ moles en $800 \mathrm{ml}$. La cantidad de $\mathrm{Ca}(\mathrm{OH})_{2}$ disuelto depende del que existe en las probetas de mortero que, en igualdad de condiciones, es función de la mezcla cemento 1 /escoria utilizada en la fabricación de las diversas series de dichas probetas. Parte del $\mathrm{Ca}(\mathrm{OH})_{2}$ formado reacciona con la escoria para dar los compuestos cálcicos como se señaló en (3).

El equilibrio (A) se ve afectado:

a) Por la presencia de los iones presentes en el agua de mar artificial (no comunes y que no reaccionen con otros iones del medio) que favorecen la solubilidad del $\mathrm{Ca}(\mathrm{OH})_{2}$; efecto salino.

b) Por la existencia de otros iones o compuestos que dan lugar a reacciones de precipitación, como son:

$$
\begin{aligned}
& \mathrm{CO}_{2}+\mathrm{Ca}(\mathrm{II})+2 \mathrm{OH}(\mathrm{I}) \longleftrightarrow \mathrm{CaCO}_{3} \text {. sólido }+\mathrm{H}_{2} \mathrm{O} \\
& \mathrm{Mg} \text { (II) }+2 \mathrm{OH}(\mathrm{I}) \longleftrightarrow \mathrm{Mg}(\mathrm{OH})_{2} \text {. sólido } \\
& \mathrm{Ca}(\mathrm{II})+\mathrm{SO}_{4}(\mathrm{II}) \stackrel{\mathrm{H}_{2} \mathrm{O}}{\Longleftrightarrow} \mathrm{CaSO}_{4} \cdot 2 \mathrm{H}_{2} \mathrm{O} \text {.sólido }
\end{aligned}
$$

que, en determinado grado, producen la disminución de iones $\mathrm{Ca}$ (II) y $\mathrm{OH}$ (I) favoreciendo, así mismo, la solubilidad del $\mathrm{Ca}(\mathrm{OH})_{2}$ y el avance de las reacciones de hidratación.

El pH del agua de mar artificial $(6,5)$ alcanza valores superiores a 11,5 y 10,6 en los medios en donde han estado sumergidas las probetas de mortero hechas con cemento 1 sin adición de escoria, o con la mezcla que tiene el $15 \%$ de escoria (en peso), respectivamente; en los medios restantes que corresponden a las series de probetas fabricadas con las mezclas cemento $1 /$ escoria $=65 / 35-40 / 60$ y $30 / 70$ (en peso) se encuentra comprendido entre 7,5 y 7,9 debido a la menor cantidad de $\mathrm{Ca}(\mathrm{OH})_{2}$ puesto en juego.

Las cantidades totales de $\mathrm{Ca}$ (II) en las fases disueltas [Ca (II) del agua de mar artificial ASTM + Ca (II) procedente de la disolución del $\mathrm{Ca}(\mathrm{OH})_{2}$ ] de cada uno de los sistemas parciales, es decir, de cada serie de probetas fabricadas con una misma mezcla cemento 1/escoria, sumergidas durante $56-90-180$ y 360 dias en agua de mar artificial ASTM, es del mismo orden (tabla 1), encontrándose los valores máximos y mínimos en un entorno pequeño (tabla 4). 
TABLA 4

Sistema: cemento 1/escoria-agua de mar artificial ASTM

Cantidades de Ca (II), máximas y mínimas, en la fase disuelta y en la fase sólida

\begin{tabular}{|c|c|c|c|c|c|c|}
\hline \multirow{2}{*}{$\begin{array}{c}\text { Mezcla } \\
\text { cemento 1/ }\end{array}$} & \multicolumn{3}{|c|}{ Fase disuelta (moles $\times 10^{-2}$ ) } & \multicolumn{3}{|c|}{ Fase sólida (moles $\times 10^{-2}$ ) } \\
\hline & $\underset{\text { máxima }}{\mathbf{X}}$ & $\underset{\text { minima }}{\mathbf{X}}$ & $\overline{\mathbf{x}}$ & $\underset{\text { máxima }}{\mathbf{X}}$ & $\underset{\text { minima }}{\mathbf{X}}$ & $\overline{\mathbf{x}}$ \\
\hline $100 / 0$ & 3,9 & 3,2 & 3,5 & 3,6 & 1,4 & 2,1 \\
\hline $85 / 15$ & 3,3 & 2,5 & 3,0 & 3,2 & 0,8 & 1,6 \\
\hline $65 / 35$ & 2,5 & 2,4 & 2,5 & 2,0 & 0,4 & 1,1 \\
\hline $40 / 60$ & 1,6 & 1,4 & 1,5 & 1,2 & 0,4 & 0,6 \\
\hline $30 / 70$ & 1,7 & 1,1 & 1,3 & 0,7 & 0,4 & 0,5 \\
\hline
\end{tabular}

Dichas cantidades de Ca (II) son directamente proporcionales al contenido de cemento 1 en la mezcla utilizada para elaborar las diversas series de probetas de mortero, presentando un aporte de $\mathrm{Ca}$ (II) que se considera aditivo, de tal modo que en la disolución se encuentran $3,5 \times 10^{-2}$ moles (valor medio) para el caso de las probetas hechas con cemento 1 y cero moles cuando no existe cemento 1 (figura 12); fenómeno que se piensa comprobar experimentalmente en otros trabajos.

$\mathrm{El} \mathrm{Ca}(\mathrm{OH})_{2}$, formado en las reacciones de hidratación de los compuestos del clínker, se ha detectado por DRX (3) en la fracción enriquecida extraida de las probetas de mortero hechas con cemento 1 sin adición de escoria y con las mezclas que tienen el menor contenido de escoria (15\%), en las tres primeras edades, y el $35 \%$ en la primera edad. En los restantes casos no se ha puesto de manifiesto, porque en estado naciente ha reaccionado parcialmente con

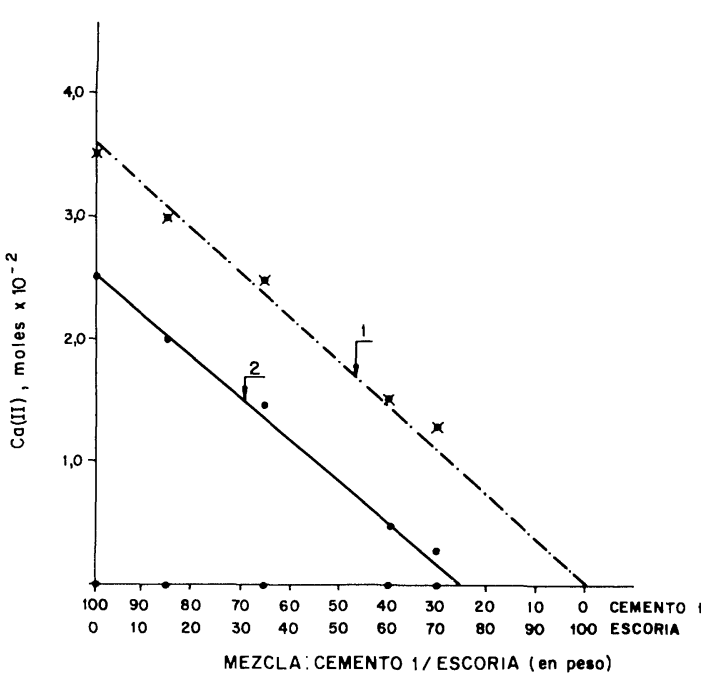

Fig. 12.-Sistema: cemento 1/escoria-agua de mar artificial ASTM.

Evolución del contenido de $\mathrm{Ca}$ (II); valores medios para todas las edades.

Gráfica $1=\mathrm{Ca}(\mathrm{II})$ en la disolución $=\mathrm{Ca}$ (II) que procede del $\mathrm{Ca}(\mathrm{OH})_{2}$ disuelto $+\mathrm{Ca}$ (II) del agua de mar.

Gráfica $2=\mathrm{Ca}$ (II) en la disolución que procede del $\mathrm{Ca}(\mathrm{OH})_{2}$ disuelto. la escoria para dar los correspondientes compuestos de calcio y con el $\mathrm{CO}_{2}$ disuelto en el agua para dar calcita en la probeta (3); el resto se ha disuelto en el agua de mar. Como las cantidades de $\mathrm{Ca}(\mathrm{OH})_{2}$ disuelto, teniendo en cuenta las presentes en el agua de mar artificial, responden cuantitativamente a los contenidos de cemento 1 de las mezclas utilizadas, (figura 12); se considera que este fenómeno es debido al avance de las reacciones de hidratación (hecho que se piensa comprobar experimentalmente en otros trabajos).

El $\mathrm{CO}_{2}$ disuelto en el agua de mar artificial ASTM es capaz de reaccionar en medio básico fuerte, como sucede en este sistema, con el Ca (II), que se encuentra en la disolución, para dar carbonato de calcio, según la reacción $(B)$ :

$$
\begin{gathered}
\mathrm{CO}_{2}+\mathrm{Ca}(\mathrm{II})+2 \mathrm{OH}(\mathrm{I}) \longleftrightarrow \\
\longleftrightarrow \mathrm{CaCO}_{3} \text {.sólido }+\mathrm{H}_{2} \mathrm{O}
\end{gathered}
$$

compuesto que ha precipitado como calcita y como aragonito, como se comprobó por DRX en (3), dando lugar a una nueva fase sólida, produ- 
ciéndose, también, una disminución de los grupos $\mathrm{OH}(\mathrm{I}) \mathrm{y}$, por consiguiente, del valor del $\mathrm{pH}$.

Esta reacción tiene lugar por cumplirse:

$$
\left[\mathrm{CO}_{3}(\mathrm{II})\right][\mathrm{Ca}(\mathrm{II})]>\mathrm{P}_{\mathrm{s}}\left(4,8 \times 10^{-9}\right)
$$

teniendo en cuenta que:

$$
\mathrm{CO}_{2}+2 \mathrm{OH}(\mathrm{I}) \longleftrightarrow \mathrm{CO}_{3}(\mathrm{II})+\mathrm{H}_{2} \mathrm{O}
$$

El Mg (II) presente en el agua de mar artificial ASTM, a pH básico fuerte, reacciona con los iones $\mathrm{OH}(\mathrm{I})$, según $(\mathrm{C})$ :

$$
\mathrm{Mg}(\mathrm{II})+2 \mathrm{OH}(\mathrm{I}) \Longleftrightarrow \mathrm{Mg}(\mathrm{OH})_{2} \text {. sólido }
$$

ya que se cumple:

$$
[\mathrm{Mg}(\mathrm{II})][\mathrm{OH}(\mathrm{I})]^{2}>\mathrm{P}^{\prime}{ }_{\mathrm{s}}\left(1,8 \times 10^{-11}\right)
$$

esta reacción lleva consigo, como en el caso anterior, una disminución de los mencionados iones $\mathrm{OH}$ (I) y, por tanto, del valor del $\mathrm{pH}$. Por medio de este proceso, parte del $\mathrm{Mg}$ (II) que existe en el agua de mar artificial ha precipitado como $\mathrm{Mg}(\mathrm{OH})_{2}$, en forma de brucita, como se probó por DRX (3) en los medios en donde han estado sumergidas las probetas de mortero elaboradas con cemento 1 y con la mezcla que tiene el menor contenido de escoria (15\%), en donde el $\mathrm{pH}$ es mayor de 10,6. Las canticiades de Mg (II) que se han encontrado en la nueva fase sólida, en estos casos, ha sido en cantidades inferiores a $0,85 \times 10^{-2}$ moles y en el agua de mar artificial en cantidades inferiores a $0,16 \times 10^{-2}$ moles en las dos primeras edades, en las otras dos no se ha detectado; del medio han desaperecido cantidades superiores a 3,5 $\times 10^{-2}$ moles de dicho ion $\mathrm{Mg}$ (II), que ha precipitado en el seno de las probetas de mortero como brucita (3), según (D):

$$
\mathrm{Mg}(\mathrm{II})+\underset{\text { (probeta) }}{\mathrm{Ca}(\mathrm{OH})_{2} \text { disuelto }} \longleftrightarrow \underset{\text { (probeta) }}{\mathrm{Mg}(\mathrm{OH})_{2} \text {. sólido }}+\mathrm{Ca} \text { (II) }
$$

de tal modo que por cada mol de iones $\mathrm{Mg}$ (II) que ha precipitado, pasa al medio otro de $\mathrm{Ca}$ (II), que reacciona con los compuestos de la escoria o se encuentra en la disolución-fase sólida. Por el contrario, en los medios en donde han estado sumergidas las probetas de mortero fabricadas con las mezclas cemento $1 /$ escoria $=65 / 35,40 / 60$ y $30 / 70$ (en peso) no ha precipitado en la disolución (no se ha encontrado en la fase sólida) por no darse las condiciones adecuadas, el pH del medio está comprendido entre 7,5 y 7,9; en estos casos el ion $\mathrm{Mg}$ (II) se encuentra en la disolución en cantidades superiores a $0,07 \times 10^{-2}$ moles para la primera mezcla y $1,3 \times 10^{-9}$ moles para las mezclas que tienen los mayores contenidos de escoria (60 y $70 \%$, en peso), habiendo desaparecido el resto, el cual por difusión ha penetrado en las probetas de mortero en donde ha precipitado como brucita (3).

En la figura 13 se ha representado la evolución del contenido de los iones Ca (II) y $\mathrm{Mg}$ (II) en la disolución más en la nueva fase sólida, en función de la mezcla cemento 1/escoria utilizada para fabricar las diversas series de probetas de mortero; en dicha figura se aprecia que ambos contenidos están intimamente relacionados, habiéndose alcanzado el equilibrio de intercambio iónico en el caso de las probetas de mortero fabricadas con las mezclas cemento 1 /escoria $=50 / 50$ (teórica), en peso, para $t=22+56$ y $22+90$ días y $40 / 60$, en peso, para $t=22+180 \mathrm{y}$ $22+360$ dias, en donde se tiene el equilibrio iónico:

$$
\begin{gathered}
\mathrm{Ca}(\mathrm{II}) \\
\text { (que pasa a la disolución) }
\end{gathered} \frac{\mathrm{Mg}(\mathrm{II})}{\text { (que desaparece de la disolución) }}
$$


que responde a los equilibrios $(\mathrm{E})$ :

$$
\begin{aligned}
& \underbrace{\mathrm{Mg}(\mathrm{II})+\mathrm{Ca}(\mathrm{OH})_{2} \text {. sólido }\left[\Longleftrightarrow \mathrm{Ca}(\mathrm{OH})_{2} \text {.disolución } \Longleftrightarrow \mathrm{Ca}(\mathrm{II})+2 \mathrm{OH}(\mathrm{I})\right]}_{\mathrm{Mg}(\mathrm{II})+\mathrm{Ca}(\mathrm{OH})_{2} \text {. sólido }} \longleftrightarrow \\
& \underbrace{\left[\mathrm{Mg}(\mathrm{II})+2 \mathrm{OH}(\mathrm{I}) \Longleftrightarrow \mathrm{Mg}(\mathrm{OH})_{2} \cdot \text { disolución } \Longleftrightarrow\right] \mathrm{Mg}(\mathrm{OH})_{2} \text {. sólido }+\mathrm{Ca}(\mathrm{II})}_{\mathrm{Mg}(\mathrm{OH})_{2} \text {. sólido }+\mathrm{Ca}(\mathrm{II})}
\end{aligned}
$$

En los casos de mezclas con cantidades inferiores de escoria a $60 \%$ ( 180 y 360 días) y $50 \%$ (56 y 90 dias), o mayores de cemento 1 , las cantidades de $\mathrm{Ca}$ (II) son superiores a las de $\mathrm{Mg}$ (II) ya que se genera más $\mathrm{Ca}(\mathrm{OH})_{2}$ durante la hidratación quedando libre, en parte, mayor cantidad que facilita la precipitación del $\mathrm{Mg}$ (II) y la solubilidad de dicho $\mathrm{Ca}(\mathrm{OH})_{2}$. Por el contrario, en los casos en donde las mezclas tienen cantidades superiores de escoria (o inferiores de cemento) a las señaladas anteriormente, se invierte el fenómeno, quedando en la disolución más en la nueva fase sólida cantidades mayores de $\mathrm{Mg}$ (II) que las de Ca (II) por no darse las condiciones para que precipite el ion $\mathrm{Mg}$ (II) al no existir, de un modo especial, suficiente concentración de iones $\mathrm{OH}$ (I), ya que no se ha generado la cantidad necesaria de $\mathrm{Ca}(\mathrm{OH})_{2}$. Los hechos mencionados influyen en el grado de resistencia química de los cementos.

En el sistema presente se debe tener en consideración el contenido total de $\mathrm{Ca}$ (II) en la disolución 「Ca (II) del agua de mar ASTM más Ca (II) que procede de la disolución del $\mathrm{Ca}(\mathrm{OH})_{2}$ ], sobre todo en la zona de contenidos elevados de escoria $(\geqslant 50-60 \%)$, en donde se considera que influye más intensamente en las condiciones de los equilibrios reseñados.

La disminución que experimenta el contenido de ion $\mathrm{SO}_{4}$ (II) en el agua de mar ASTM $\left(2,44 \times 10^{-2}\right.$ moles $\left./ 800 \mathrm{ml}\right)$ está intimamente ligada a las caracteristicas del cemento y de la escoria, así como a la mezcla utilizada para fabricar las probetas y al tiempo de conservaciónataque, que influyen en la formación de compuestos a base de sulfatos (yeso secundario y ettringita) en las probetas de mortero, como se probó por DRX en (3), al reaccionar con los iones $\mathrm{Ca}$ (II), procedentes del $\mathrm{Ca}(\mathrm{OH})_{2}$, y con el aluminato de calcio hidratado del cemento según $(\mathrm{F})$ y $(G)$ :
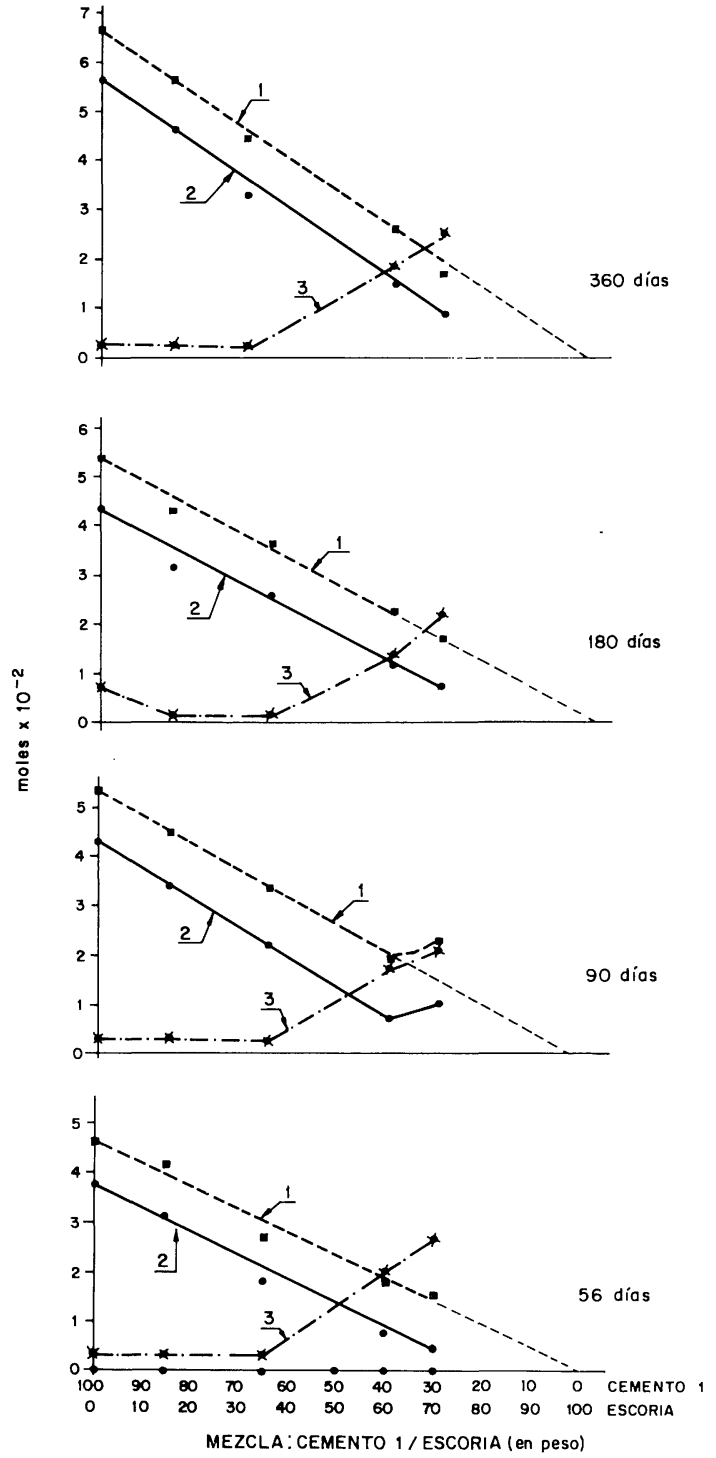

Fig. 13.-Sistema: cemento 1/escoria-agua de mar artificial ASTM.

Evolución de los contenidos de $\mathrm{Ca}$ (II) y de $\mathrm{Mg}$ (II).

Gráfica $1=\mathrm{Ca}$ (II) en la disolución + en la fase sólida. $\mathrm{Ca}$ (II) en la disolución $=\mathrm{Ca}$ (II) que procede del $\mathrm{Ca}(\mathrm{OH})_{2}$ disuelto $+\mathrm{Ca}$ (II) del agua de mar.

Gráfica $2=\mathrm{Ca}$ (II) en la disolución + en la fase sólida. $\mathrm{Ca}$ (II) en la disolución $=\mathrm{Ca}$ (II) que procede del $\mathrm{Ca}(\mathrm{OH})_{2}$ disuelto.

Gráfica $3=\mathrm{Mg}$ (II) en la disolución + en la fase sólida. 


$$
\mathrm{Ca}(\mathrm{II})+\mathrm{SO}_{4}(\mathrm{II})+2 \mathrm{H}_{2} \mathrm{O} \Longleftrightarrow \mathrm{CaSO}_{4} \cdot 2 \mathrm{H}_{2} \mathrm{O}
$$

(G) $3 \mathrm{Ca}$ (II) $+3 \mathrm{SO}_{4}$ (II) $+3 \mathrm{CaO} \cdot \mathrm{Al}_{2} \mathrm{O}_{3} \cdot 12 \mathrm{H}_{2} \mathrm{O}+19 \mathrm{H}_{2} \mathrm{O} \Longleftrightarrow 3 \mathrm{CaO}_{2} \mathrm{Al}_{2} \mathrm{O}_{3} \cdot 3 \mathrm{CaSO}_{4} \cdot 31 \mathrm{H}_{2} \mathrm{O}$ $3 \mathrm{CaSO}_{4} \cdot 2 \mathrm{H}_{2} \mathrm{O}$

y con los aluminatos de la escoria y el $\mathrm{Ca}(\mathrm{OH})_{2}$ del cemento hidratado, según el equilibrio $(\mathrm{H})$ :

$$
\begin{aligned}
2 \mathrm{CaO}_{2} \mathrm{Al}_{2} \mathrm{O}_{3} & +\mathrm{Ca}(\mathrm{OH})_{2}+\frac{3 \mathrm{Ca}(\mathrm{II})+3 \mathrm{SO}_{4}(\mathrm{II})}{3 \mathrm{CaSO}_{4} \cdot 2 \mathrm{H}_{2} \mathrm{O}}+30 \mathrm{H}_{2} \mathrm{O} \longleftrightarrow \\
\text { escoria vitrea } & \longleftrightarrow 3 \mathrm{CaO} \cdot \mathrm{Al}_{2} \mathrm{O}_{3} \cdot 3 \mathrm{CaSO}_{4} \cdot 31 \mathrm{H}_{2} \mathrm{O}
\end{aligned}
$$

lo que hace que, para un clínker y una escoria dados, la cantidad de escoria en la mezcla empleada para fabricar las series de probetas influya en la cantidad de iones $\mathrm{SO}_{4}$ (II) fijados para formar ettringita, presentando, a veces, valores de la misma magnitud que en el caso de utilizar el cemento 1 sin adición de escoria.

La eliminación de iones Cl (I) del agua de mar artificial ASTM $\left(44,2 \times 10^{-2}\right.$ moles $\left./ 800 \mathrm{ml}\right) \mathrm{se}$ debe a la formación de la sal de Friedel en las probetas de mortero, por reacción de dichos iones $\mathrm{Cl}$ (I) con los iones $\mathrm{Ca}$ (II), procedentes del $\mathrm{Ca}(\mathrm{OH})_{2}$, y con los aluminatos de calcio hidratados o sus derivados, o con el $\mathrm{C}_{4} \mathrm{AF}$ o sus disoluciones sólidas, según (I):

$$
\underbrace{2 \mathrm{Cl}(\mathrm{I})+\mathrm{Ca}(\mathrm{II})}_{\mathrm{CaCl}_{2}}+3 \mathrm{CaO} \cdot \mathrm{Al}_{2} \mathrm{O}_{3} \cdot 6 \mathrm{H}_{2} \mathrm{O}+4 \mathrm{H}_{2} \mathrm{O} \Longleftrightarrow 3 \mathrm{CaO} \cdot \mathrm{Al}_{2} \mathrm{O}_{3} \cdot \mathrm{CaCl}_{2} \cdot 10 \mathrm{H}_{2} \mathrm{O}
$$

La cantidad de iones $\mathrm{Cl}$ (I) eliminados de la disolución depende, en estos casos, de la mezcla cemento 1/escoria utilizada en la elaboración de las probetas de mortero y del tiempo de conservación-ataque; las cantidades menores de iones $\mathrm{Cl}$ (I) en el medio, o mayores que han desaparecido del mismo, corresponden al agua de mar artificial ASTM en donde han estado sumergidas las series de probetas hechas con las mezclas que tienen $35 \%$, generalmente, y $60 \%$ de escoria (en peso), como sucede en los casos de eliminación de iones $\mathrm{SO}_{4}$ (II); hecho que induce a pensar que la escoria también influye en la formación de los compuestos correspondientes.

\section{CONCLUSIONES}

\section{Primera}

En el agua de mar artificial ASTM (D 1141-75) en donde han estado sumergidas las diversas series de probetas de mortero $(1: 3)$ hechas con un cemento portland de alta resistencia inicial (cemento 1) y con las mezclas cemento 1 /escoria estudiadas en este trabajo $(85 / 15,65 / 35$, $40 / 60$ y $30 / 70$, en peso) se produce una variación de la concentración de los iones $\mathrm{Ca}$ (II), $\mathrm{Mg}$ (II), $\mathrm{SO}_{4}$ (II) y $\mathrm{Cl}$ (I) - aumento del primero y disminución de los restantes-, un incremento del valor del $\mathrm{pH}$ y la formación de una nueva fase sólida, que son función de la mezcla utilizada para fabricar las mencionadas series de probetas y del tiempo de conservación-ataque.

\section{Segunda}

La cantidad de fase sólida formada en los medios (agua de mar artificial) en donde han estado sumergidas las diversas series de probetas hechas con una misma mezcla aumenta con el tiempo de conservación-ataque y disminuye para una misma edad, según lo hace la cantidad de cemento 
en la mezcla utilizada para fabricar dichas probetas. El mencionado aumento es mínimo cuando se trata de los medios en donde han estado las series de probetas fabricadas con las mezclas que tienen los contenidos menores de cemento (40 y $30 \%$, en peso) y, por consiguiente, los mayores de escoria (60 y $70 \%$, en peso, respectivamente).

\section{Tercera}

El contenido de $\mathrm{Ca}$ (II) en la fase líquida más en la nueva fase sólida, que procede, de un modo especial, del $\mathrm{Ca}(\mathrm{OH})_{2}$ disuelto del cemento hidratado, para cada mezcla cemento 1/escoria utilizada en la fabricación de las distintas series de probetas de mortero, aumenta con el tiempo de conservación-ataque y, para cada edad, disminuye bruscamente conforme lo hace el contenido de cemento 1 de la mencionada mezcla cemento 1 /escoria.

Los contenidos totales de $\mathrm{Ca}$ (II) [Ca (II) que corresponde al agua de mar artificial ASTM + Ca (II) que se encuentra en la disolución y en la nueva fase sólida, procedente del $\mathrm{Ca}(\mathrm{OH})_{2}$ disueltol de cada conjunto de probetas elaboradas con el cemento 1 y con las diversas mezclas cemento 1/escoria, para cada edad, responde, prácticamente, a las cantidades teóricas referidas al contenido de cemento 1, calculadas a partir del contenido total de $\mathrm{Ca}$ (II) del agua de mar artificial ASTM en donde han estado sumergidas las series de probetas hechas con dicho cemento 1 .

\section{Cuarta}

El contenido de $\mathrm{Mg}$ (II) del agua de mar artificial ASTM, en donde han estado sumergidas las diversas series de probetas de mortero, experimenta una disminución que es función de la mezcla cemento 1/escoria empleada en la elaboración de las mencionadas series de probetas de mortero y del tiempo de conservación-ataque.

El ion $\mathrm{Mg}$ (II) ha desaparecido, prácticamente, de dicha agua de mar artificial en donde han estado las series de probetas hechas con cemento 1 y con la mezcla que tiene $15 \%$ de escoria, en donde, parcialmente, ha precipitado como $\mathrm{Mg}(\mathrm{OH})_{2}$, al estado de brucita. En los casos restantes se encuentra en la fase líquida en cantidades diversas, no habiéndose detectado en la nueva fase sólida.

\section{Quinta}

La evolución del contenido de $\mathrm{Ca}$ (II) está íntimamente ligada con la del $\mathrm{Mg}$ (II), de tal modo que cuando el del primero - Ca (II) - aumenta, el del segundo - $\mathrm{Mg}$ (II) - disminuye y viceversa. En este sistema, y según las edades, existe un punto que corresponde al equilibrio iónico $\mathrm{Ca}$ (II) $\Longleftrightarrow \mathrm{Mg}$ (II).

\section{Sexta}

El contenido de $\mathrm{SO}_{4}$ (II) del agua de mar artificial ASTM, en donde han estado sumergidas las diversas series de probetas de mortero, experimenta una disminución que es más pronunciada en los medios correspondientes a las probetas de mortero hechas con cemento $1 \mathrm{y}$ con las mezclas que tienen 15 y $35 \%$ de escoria (en peso). En estos casos la cantidad de iones sulfato se hace menor conforme aumenta el tiempo de conservación-ataque.

En el agua de mar artificial ASTM en donde han estado durante las 4 edades las series restantes de probetas de mortero, elaboradas con las mezclas cemento $1 /$ escoria $=40 / 60 \mathrm{y}$ $30 / 70$ (en peso), las cantidades de $\mathrm{SO}_{4}$ (II) son del mismo orden. 


\section{Séptima}

El contenido de $\mathrm{Cl}$ (I) del agua de mar artificial ASTM en donde han estado sumergidas las distintas series de probetas de mortero experimenta una disminución (ligera), que es función de la mezcla cemento 1 /escoria utilizada en su fabricación.

Las mayores cantidades, aproximadamente del mismo orden que la del agua de mar artificial, se presentan en los medios en donde han estado sumergidas las series de probetas hechas con cemento 1 y las menores en el agua de mar artificial que corresponde a las series de probetas fabricadas con las mezclas que tienen 35 y $60 \%$ de escoria (en peso), de un modo especial $35 \%$.

\section{BIBLIOGRAFIA}

(1) SAGRERA-MORENO, J. L. y GASPAR-TEBAR, D. (1980): Resistencia química del hormigón: IV. Acción del agua de mar: influencia de la adición de escoria a un cemento portland de alta resistencia inicial. Evolución de las resistencias mecánicas a flexotracción y del coeficiente de corrosión. Materiales de Construcción, abril, mayo, junio, 178, 17-38.

(2) GASPAR-TEBAR, D. y SAGRERA-MORENO, J. L. (1981): Resistencia quimica del hormigón: IX. Influencia de la adición de escoria a un cemento portland de alta resistencia inicial. Estudio por DRX del sistema cemento 1/escoria-agua potable filtrada. Materiales de Construcción, enero-febrero-marzo, 181, 33-34.

(3) GASPAR-TEBAR, D. y SAGRERA-MORENO, J. L. (1982): Resistencia quimica del hormigón: XVI. Acción del agua de mar: influencia de la adición de escoria a un cemento portland de alta resistencia inicial. Estudio por DRX. Materiales de Construcción, abril-mayo-junio, 186, 39-60.

(4) SAGRERA-MORENO, J. L. y GASPAR-TEBAR, D. (1983): Resistencia quimica del hormigón: XXI. Acción del agua de mar: influencia de la adición de escoria a un cemento portland de alta resistencia inicial. Estudio de la concentración iónica del sistema cemento 1/escoria-agua potable filtrada. Materiales de Construcción, octubre-noviembre-diciembre, 192, 33-41.

(5) BICZOK, J. (1972): Corrosión y Protección del Hormigón. Ed. Urmo, Bilbao, pág. 211.

\section{RECONOCIMIENTO}

Nuestro más sincero reconocimiento a las personas del Equipo de Durabilidad del IETcc: Amalia Rodríguez Pereira, Lucila López Solana, Felipe Cantero Palacios y Manuel Cantero Palacios por su valiosa colaboración en la realización de este trabajo. 